\section{Request for Comments}

Comments are invited on: (a) Whether the proposed collection of information is necessary for the proper performance of the functions of the agency, including whether the information shall have practical utility; (b) The accuracy of the agency's estimate of the burden (including hours and cost) of the proposed collection of information; (c) Ways to enhance the quality, utility, and clarity of the information to be collected; and (d) Ways to minimize the burden of the collection of information on respondents, including through the use of automated collection techniques or other forms of information technology.

The Census Bureau will summarize and/or include comments submitted in response to this notice in the request for OMB approval of this information collection; the comments also will become a matter of public record.

Dated: May 21, 2010.

Glenna Mickelson,

Management Analyst, Office of the Chief Information Officer.

[FR Doc. 2010-12626 Filed 5-25-10; 8:45 am] BILLING CODE 3510-07-P

\section{DEPARTMENT OF COMMERCE}

\section{Bureau of the Census}

[Docket Number 100429203-0204-01]

\section{Developing a Supplemental Poverty Measure}

AGENCY: Bureau of the Census, Department of Commerce.

ACTION: Notice and solicitation of comments.

SUMmARY: The Bureau of the Census (Census Bureau) issues this notice to request comments on the approach to developing a Supplemental Poverty Measure (SPM) presented in a report entitled "Observations from the Interagency Technical Working Group on Developing a Supplemental Poverty Measure," which was recently released by the Interagency Technical Working Group on Developing a Supplemental Poverty Measure (Working Group). This report was produced as part of an effort by the Working Group to suggest how the Census Bureau, in cooperation with the U.S. Department of Labor's Bureau of Labor Statistics (BLS), should develop a new Supplemental Poverty Measure. The report provides observations about how to make a series of initial choices in the development of the SPM. The eventual publication of the SPM will not replace the official poverty measure, nor will it have any impact on allocations determined by the poverty measurement. Rather, it is part of the Census Bureau's ongoing effort to more accurately measure poverty levels in the United States.

DATES: To ensure consideration, written comments must be submitted to the office listed in the ADDRESSES section of this notice on or before June 25, 2010.

ADDRESSES: Send comments to David Johnson, Housing and Household Economic Statistics Division, Census Bureau, 4600 Silver Hill Road, Stop 8500, Washington, DC 20233-8500 or to spm@census.gov. The Interagency Technical Working Group's report may be found at: http://www.census.gov/ hhes/www/poverty/SPM

TWGObservations.pdf.

FOR FURTHER INFORMATION CONTACT: David Johnson, Housing and Household Economic Statistics Division, Census Bureau, telephone number 301-7636443 (this is not a toll-free number), email to:spm@census.gov.

SUPPLEMENTARY INFORMATION:

\section{Background}

Since the publication of the first official U.S. poverty estimates in 1964, there has been continuing debate about the best approach to measuring poverty in the United States. Recognizing that supplemental estimates of poverty can provide very useful information to the public as well as to the Federal Government, in 2009, the Office of Management and Budget's (OMB) Chief Statistician formed an Interagency Technical Working Group on Developing a Supplemental Poverty Measure (Working Group). This group included representatives from BLS, the Census Bureau, the Economics and Statistics Administration, the Council of Economic Advisers, the U.S.

Department of Health and Human Services, and OMB. The Working Group asked the Census Bureau, in cooperation with the Bureau of Labor Statistics, to develop a Supplemental Poverty Measure (SPM) to obtain an improved understanding of the economic wellbeing of American families and of how Federal policies affect those living in poverty, and offered its observations on how the Census Bureau should do so in the above-referenced report.

The SPM ultimately produced by the Census Bureau would not replace the official poverty measure, and the SPM will not be the measure used to estimate eligibility for government programs. The official statistical poverty measure, as defined in OMB Statistical Policy Directive No. 14, will continue to be produced and updated every year. The
SPM is instead designed as an experimental measure that defines income thresholds and resources in a manner different from the official poverty measure. The Census Bureau considers the SPM a work in progress, and both the Working Group and the Census Bureau expect that there will be improvements to the SPM over time. The first publication of the SPM will be accompanied by a detailed description of the methodology used to estimate the new supplemental measure, and the Census Bureau expects to update this description as changes are incorporated in the SPM.

The new supplemental measure would be published initially in the fall of 2011 at the same time and level of detail as the 2010 income and poverty statistics that reflect the official poverty measure, and annually thereafter. Developing and estimating an SPM will take substantial advance work and planning, and the Working Group's observations are meant to assist the Census Bureau and the BLS in such planning.

\section{Defining the Supplemental Poverty Measure}

In its report, the Working Group laid out a series of suggestions and recommendations that, taken together, provide a roadmap through which the Census Bureau, with the assistance of BLS, can use to produce the initial set of estimates of the number and percentage of people in poverty based on the SPM in 2011. It is likely that the procedures used to create this first set of estimates will closely resemble the Working Group's recommendations. A much abbreviated summary of the group's suggestions follows. The Census Bureau invites the public to read and offer comments on the approach described in the Working Group's full report, which can be found at http:// www.census.gov/hhes/www/poverty/ SPM TWGObservations.pdf. The Census Bureau is especially interested in receiving comments on the methodology the Working Group employed in making its recommendations.

The poverty threshold is the annual expenditure amount below which a family is considered poor. The Working Group recommended that the poverty threshold for the SPM should be established on the basis of expenditures for commodities that all families must purchase: Food, shelter, clothing, and utilities (collectively, FSCU). This threshold should be derived from expenditure data from BLS' U.S. Consumer Expenditure Survey. The Working Group recommended that the reference sample for this threshold be 
an average of all families with exactly two children. A "family unit" should consist of all related individuals who live at the same address, any co-resident unrelated children who are cared for by the family, and any cohabiters and their children. Using the most recent fiveyear distribution of FSCU expenditures, the Working Group recommended that the Census Bureau set the dollar amount of the poverty threshold at the 33rd percentile of the distribution of FCSU expenditures. To account for differences among those who rent, own a home with a mortgage, and own a home without a mortgage, the Working Group recommended the Census Bureau develop an adjustment factor for the shelter component, to reflect differences in expenditures among these three groups. To account for basic expenditures outside of FCSU, the Working Group recommended that the Census Bureau multiply the dollar amount (as calculated above) by 1.2. To define thresholds for different families, the Working Group recommended the use of the so-called "three-parameter equivalence scale" that has been used by the Census in recent years. The Working Group also recommended that thresholds be updated annually using an updated five-year distribution of FSCU expenditures.

The Working Group also recommended that poverty thresholds should be adjusted for price differences across geographic areas. American Community Survey (ACS) data, which is collected annually by the Census Bureau, appear to be the best data currently available from which one can create a housing price index based on differences in rental prices of housing across areas. Future work may provide price data that can be used to measure interarea price differentials on more items than housing alone.

To determine poverty status under the SPM, resources (income plus noncash benefits, minus necessary expenses) are compared to a family's poverty threshold (as calculated in the method described above). If a family's resources are below its poverty threshold, that family and all persons in the family are counted as poor. The Working Group recommended that family resources be estimated as the sum of cash income, plus any Federal government in-kind benefits that families can use to meet their FCSU. From this amount, the Working Group recommended subtracting taxes (or adding tax credits), work expenses, child support paid, and out-of-pocket medical expenses to determine poverty status. The survey used to make these calculations will be the Current Population Survey's Annual
Social and Economic Supplement, (CPS ASEC), which is jointly sponsored by the Census Bureau and BLS.

Work expenses have an impact on poverty status. The Working Group therefore recommended that the definition of resources used to calculate the SPM should exclude expenses associated with commuting and child care. For child care, the Working Group recommended that actual expenses, either reported on the CPS ASEC or assigned to CPS ASEC families based on other household surveys that collect these data, should be used. For other work expenses, the Working Group recommended that the Census Bureau investigate the advantages and disadvantages of using actual expenses versus an average amount for all working adults.

To account for medical out-of-pocket (MOOP) expenses, the Working Group recommended that the Census Bureau examine the reliability of questions newly added to the CPS ASEC in 2010. If these data are found to be reliable, the Working Group recommended that the Census Bureau use data from the CPS ASEC in the calculation of family resources. If these data are found to be unreliable, then the Working Group recommended that MOOP should be assigned to CPS ASEC families and individuals from other surveys that collect reliable information on MOOP, in a way that takes into account the differences in medical expenses among demographic groups. The Working Group also suggested that the Census Bureau investigate the advantages and disadvantages of adjusting MOOP for those who are uninsured, to reflect that the uninsured may be paying less than is customary because they lack health insurance and cannot pay for health services.

\section{Desired Focus of Comments}

While the Census Bureau welcomes public comments on the approaches described in the report of the Working Group, the Census Bureau is particularly interested in receiving comments on the specific methods used in the report, to ensure that the Census Bureau uses best practices in developing the SPM. Specifically, the Census Bureau is interested in comments on:

- Methods and data sources used to geographically adjust poverty thresholds;

- Methods and data sources used to adjust resources to account for child care and other work-related expenses;

- Methods and data sources used to adjust resources to account for medical out-of-pocket expenses; and
- Methods and data sources used to impute dollar values for in-kind benefits and taxes.

For more information on the Working Group's observations on the components for the new SPM, see the report entitled "Observations from the Interagency Technical Working Group on Developing a Supplemental Poverty Measure." For more information/ background on issues related to alternative poverty measures, see http://www.census.gov/hhes/www/ povmeas/papers.html.

Dated: May 18, 2010.

Robert M. Groves,

Director, Bureau of the Census.

[FR Doc. 2010-12628 Filed 5-25-10; 8:45 am] BILLING CODE 3510-07-P

\section{DEPARTMENT OF COMMERCE}

\section{International Trade Administration}

[Application No. 10-00001]

\section{Export Trade Certificate of Review}

ACTION: Notice of Issuance of an Export Trade Certificate of Review to Alaska Longline Cod Commission (Application No. 10-00001).

SUMmARY: On May 13, 2010, the U.S. Department of Commerce issued an Export Trade Certificate of Review to the Alaska Longline Cod Commission (“ALCC”). This notice summarizes the conduct for which certification has been granted.

FOR FURTHER INFORMATION CONTACT:

Joseph E. Flynn, Director, Office of Competition and Economic Analysis, International Trade Administration, by telephone at (202) 482-5131 (this is not a toll-free number), or by E-mail at oetca@ita.doc.gov.

SUPPLEMENTARY INFORMATION: Title III of the Export Trading Company Act of 1982 (15 U.S.C. Sections 4001-21) authorizes the Secretary of Commerce to issue Export Trade Certificates of Review. The regulations implementing Title III are found at 15 CFR Part 325 (2009).

The Office of Competition and Economic Analysis is issuing this notice pursuant to 15 CFR section 325.6(b), which requires the Secretary of Commerce to publish a summary of the certification in the Federal Register. Under Section 305(a) of the Act and 15 CFR section 325.11(a), any person aggrieved by the Secretary's determination may, within 30 days of the date of this notice, bring an action in any appropriate district court of the United States to set aside the 